\title{
TRUEX Partitioning from Radioactive ICPP Sodium Bearing Waste
}

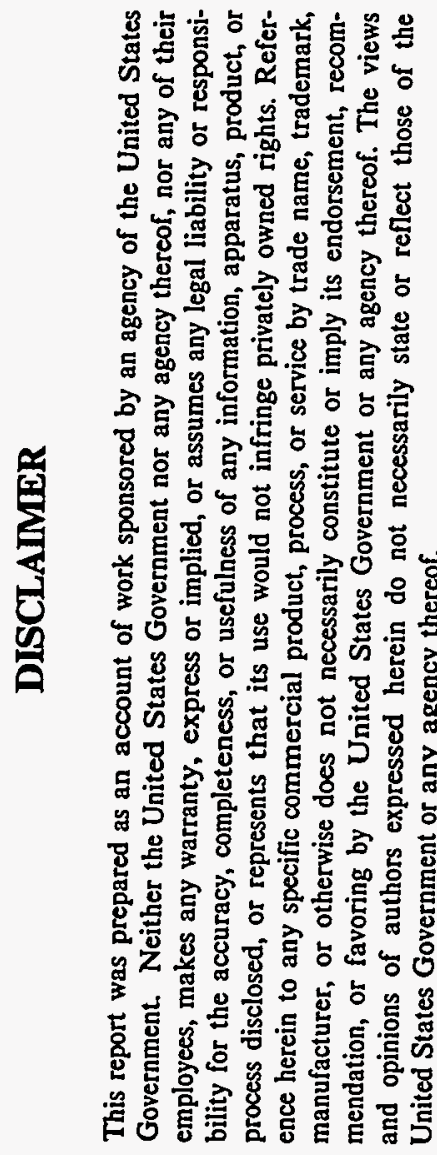

\author{
R. S. Herbst \\ K. N. Brewer \\ T. J. Tranter \\ T. A. Todd \\ Published March 1995 \\ Idaho National Engineering Laboratory \\ HLW Engineering and Projects Department \\ Lockheed Idaho Technologies Company \\ Idaho Falls, Idaho 83415
}

Prepared for the

U.S. Department of Energy

Assistant Secretary for Environmental Management

Under DOE Idaho Operations Office

Contract DE-AC07-94ID13223 
MTRMW 


\section{DISCLAIMER}

Portions of this document may be illegible in electronic image products. Images are produced from the best available original document. 


\begin{abstract}
The Idaho Chemical Processing Plant (ICPP) located at the Idaho National Engineering Laboratory in Southeast Idaho is currently evaluating several treatment technologies applicable to waste streams generated over several decades of nuclear fuel reprocessing. Liquid sodium bearing waste (SBW), generated primarily during decontamination activities, is one of the waste streams of interest. The TRans Uranic EXtraction (TRUEX) process developed at Argonne National Laboratory is currently being evaluated to separate the actinides from SBW. On a mass basis, the amount of the radioactive species in SBW are low relative to inert matrix components. Thus, the advantage of separations is a dramatic decrease in resulting volumes of high activity waste (HAW) which must be dispositioned. Numerous studies conducted at the ICPP indicate the applicability of the TRUEX process has been demonstrated; however, these studies relied on a simulated SBW surrogate for the real waste. Consequently, a series of batch contacts were performed on samples of radioactive ICPP SBW taken from tank WM-185 to verify that actual waste would behave similarly to the simulated waste.
\end{abstract}

The test results with SBW from tank WM-185 indicate the TRUEX solvent effectively extracts the actinides from the samples of actual waste. Gross alpha radioactivity, attributed predominantly to $\mathrm{Pu}$ and $\mathrm{Am}$, was reduced from $3.14 \mathrm{E}+04 \mathrm{dps} / \mathrm{mL}$ to $1.46 \mathrm{dps} / \mathrm{mL}$ in three successive batch contacts with fresh TRUEX solvent. This reduction corresponds to a decontamination factor of $D F=20,000$ or $99.995 \%$ removal of the gross $\alpha$ activity in the feed. The distribution coefficients ( $D$ 's) for extraction of the individual actinides ranged from $D_{\mathrm{Pu}}=$ 50,000 to $D_{A m}=17$, which is sufficient to insure a low activity waste (LAW) fraction can be produced substantially below the $10 \mathrm{nCi} / \mathrm{g}$ NRC Class $A$ transuranic limits. The TRUEX solvent also extracted the matrix components $\mathrm{Zr}, \mathrm{Fe}$, and $\mathrm{Hg}$ to an appreciable extent $\left(\mathrm{D}_{\mathrm{zr}}>10, \mathrm{D}_{\mathrm{Fe}} \sim 2\right.$, $D_{\mathrm{Hg}} \sim 6$ ). Iron co-extracted with the actinides can be successfully scrubbed from the organic with $0.2 \mathrm{M} \mathrm{HNO}_{3}$. Mercury can be selectively partitioned from the actinides with either sodium carbonate or nitric acid ( $\geq 5 \mathrm{M} \mathrm{HNO}_{3}$ ) solutions. The co-extracted zirconium will follow the actinides to the HAW fraction with the scrub and strip solutions which were tested.

Three different stripping solutions for back-extraction of the actinides from-loaded TRUEX solvent were evaluated. The class of compounds known as thermally unstable complexants (TUCS) proved to be the most effective reagent for stripping all species, with the exception of mercury, from the organic phase. All of the measured distribution coefficients with the $0.25 \mathrm{M}$ TUCS strip solution were substantially less than one. Dilute nitric acid $(0.01 \mathrm{M}$ $\mathrm{HNO}_{3}$ ) effectively back-extracted all of the metals except $\mathrm{Pu}, \mathrm{U}$, and $\mathrm{Hg}$ from the loaded TRUEX solvent. The third strip solution tested, dilute ammonium oxalate, $0.1 \underline{\mathrm{M}}\left(\mathrm{NH}_{4}\right)_{2} \mathrm{C}_{2} \mathrm{O}_{4}$, resulted in the formation of precipitates during the strip contacts.

The results obtained with actual, radioactive ICPP SBW generally parallelled those obtained with the simulant and radioactive tracers. Consequently, the SBW simulant is a valid surrogate for use in future flowsheet development work. 
$-\ldots,-\quad, \ldots \ldots \ldots$ 


\section{ACKNOWLEGEMENTS}

The authors wish to express their sincere gratitude to C. W. Lundholm, G. D. Decoria, and J. P. Henscheid of the Remote Analytical Laboratory for the many hours of support they provided during this experiment, both in actually conducting the tests and for performing numerous analyses. Also, we greatly appreciate the assistance of I. D. Goodwin and B. J. Storms of the Radiochemistry Department for the many efficient and diligent radionuclide analyses which they performed during this series of experiments. Without the help and support of these dedicated individuals, this work would not have been possible. 


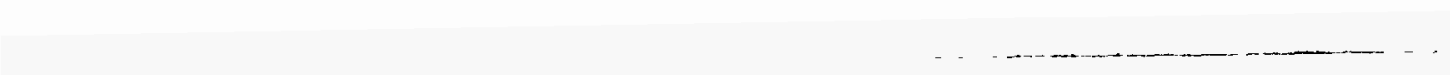




\section{TABLE OF CONTENTS}

ABSTRACT $\ldots \ldots \ldots \ldots \ldots \ldots \ldots \ldots \ldots \ldots \ldots \ldots \ldots \ldots \ldots \ldots \ldots \ldots \ldots$

ACKNOWLEGEMENTS $\ldots \ldots \ldots \ldots \ldots \ldots \ldots \ldots \ldots \ldots \ldots \ldots \ldots$

TABLE OF CONTENTS $\ldots \ldots \ldots \ldots \ldots \ldots \ldots \ldots \ldots \ldots \ldots \ldots \ldots \ldots$ vii

LIST OF FIGURES $\ldots \ldots \ldots \ldots \ldots \ldots \ldots \ldots \ldots \ldots \ldots \ldots \ldots \ldots \ldots$

LIST OF TABLES $\ldots \ldots \ldots \ldots \ldots \ldots \ldots \ldots \ldots \ldots \ldots \ldots \ldots \ldots \ldots \ldots$

INTRODUCTION $\ldots \ldots \ldots \ldots \ldots \ldots \ldots \ldots \ldots \ldots \ldots \ldots \ldots \ldots \ldots \ldots$

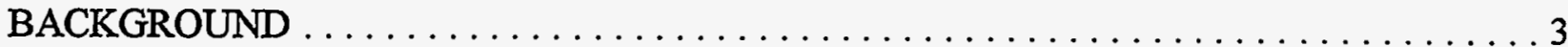

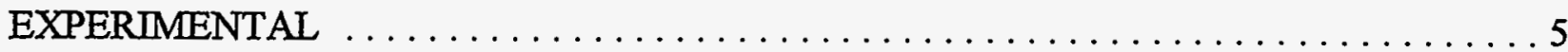

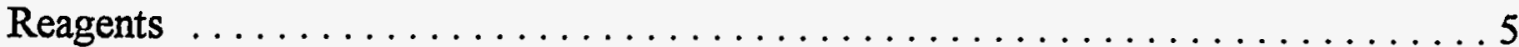

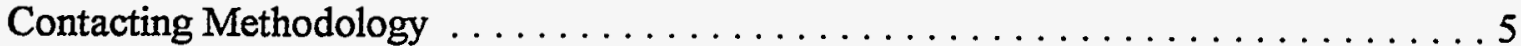

Distribution Coefficients . . . . . . . . . . . . . . . . . . . . . . 6

Characterization of WM-185 Waste $\ldots \ldots \ldots \ldots \ldots \ldots \ldots \ldots \ldots \ldots$

RESULTS AND DISCUSSION $\ldots \ldots \ldots \ldots \ldots \ldots \ldots \ldots \ldots \ldots \ldots$

Waste Decontamination Experiment $\ldots \ldots \ldots \ldots \ldots \ldots \ldots \ldots \ldots \ldots$

Solvent Loading \& Stripping Experiment $\ldots \ldots \ldots \ldots \ldots \ldots \ldots \ldots \ldots$

CONCLUSIONS $\ldots \ldots \ldots \ldots \ldots \ldots \ldots \ldots \ldots \ldots \ldots \ldots \ldots \ldots \ldots \ldots$

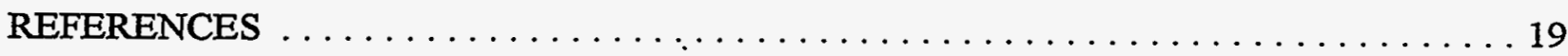

APPENDIX:

EXPERIMENTAL DATA 
... - - - 


\section{LIST OF FIGURES}

Figure 1. Experimental flow sheet used in the first $\mathrm{SBW}$ test $\ldots \ldots \ldots \ldots \ldots \ldots \ldots$

Figure 2. Experimental flowsheet used in the second WM-185 test $\ldots \ldots \ldots \ldots \ldots \ldots 13$

\section{LIST OF TABLES}

Table 1. Summary of the results obtained for simulated SBW and radioactive tracers $[3,4] \ldots 3$

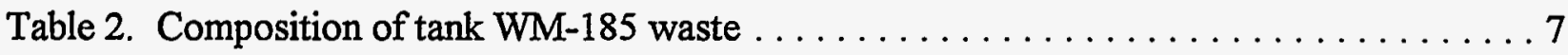

Table 3. Results from the waste decontamination experiment $\ldots \ldots \ldots \ldots \ldots \ldots \ldots$

Table 4. Results of the solvent loading and stripping test $\ldots \ldots \ldots \ldots \ldots \ldots \ldots \ldots$ 


\section{INTRODUCTION}

The Idaho Chemical Processing Plant (ICPP), located at the Idaho National Engineering Laboratory, formerly reprocessed spent nuclear fuel to recovery uranium. Fuel elements were completely dissolved with nitric and hydrofluoric acids in the headend process. Uranium was recovered from the acidic dissolver product in PUREX/REDOX type processes. After uranium recovery, the liquid raffinates were temporarily stored and ultimately calcined into a solid, granular material. Equipment cleanup and decontamination between reprocessing campaigns was performed with solutions typically high in sodium. This secondary decontamination waste, or sodium-bearing waste (SBW), is temporarily stored in the tank farm. The SBW cannot be calcined directly due to bed agglomeration associated with sodium nitrate. Historically, SBW was blended with first cycle raffinates and calcined. As of 1994, all stored reprocessing raffinates were calcined, eliminating the blending option to deplete SBW inventories. Currently, there are approximately 5.6 million liters of SBW stored in tanks at the ICPP.

The United States Environmental Protection Agency and the Idaho Department of Health and Welfare filed a Notice of Noncompliance in 1992 contending the underground SBW tanks do not meet secondary containment requirements as set forth in Title 40, Part 265.13 of the Code of Federal Regulations. Consequently, the Department of Energy has agreed to remove SBW from some of the storage tanks by the year 2009, and from the remaining tanks by 2015 .

Several technologies are currently being evaluated for the treatment and final disposition of all SBW inventories [1]. These technologies include: blending with nonradioactive chemicals, essentially diluting sodium, and calcination of the liquid; radionuclide partitioning and immobilization of the resulting high activity (HAW) and low activity (LAW) waste streams; and, numerous pretreatment options to remove sodium, concentrate the liquid, or remove nitrate followed by direct calcination.

The major emphasis at the ICPP directed toward actinide removal from SBW is the evaluation of the TRans Uranic EXtraction (TRUEX) extraction process developed by Horwitz and coworkers at Argonne National Laboratory [2]. The active extractant in the TRUEX process is octyl(phenyl)-N,N-diisobutyl-carbamoylmethylphosphine oxide (CMPO). Tributylphosphate (TBP) is added to the solvent as a phase modifier, to prevent third phase formation, with a paraffinic hydrocarbon used as the diluent. The process has been effectively used to remove actinides from acidic simulants and real wastes to well below the $10 \mathrm{nCi} / \mathrm{g}$ NRC Class $\mathrm{A}$ transuranic waste requirements. Typical solvent extraction tests have used batch contacts or small-scale continuous countercurrent extractions to evaluate the efficiency of the TRUEX process. Large scale application, as of yet, has not been realized. However, the TRUEX process has received the attention of virtually every country with nuclear processing capabilities. 



\section{BACKGROUND}

The TRUEX process has been extensively studied at the ICPP using nonradioactive SBW simulant spiked with radioactive tracer solutions. The details and a full discussion of the results are presented elsewhere $[3,4]$, and indicate the TRUEX process will efficiently remove the actinides from SBW resulting in a LAW fraction well below the $10 \mathrm{nCi} / \mathrm{g} \mathrm{NRC}$ Class A transuranic waste requirements and significantly reducing the volume of HAW. The results of the traced simulant tests pertinent to this study are summarized in Table 1 for subsequent comparison. A baseline TRUEX flowsheet was proposed based on the results in Table 1 for treatment of ICPP SBW using centrifugal contactors in a countercurrent flow arrangement [3]. The proposed flowsheet consists of 5 extraction stages, 4 scrub stages using a $0.2 \underline{\mathrm{M}} \mathrm{HNO}_{3}$ scrub, 5 strip stages with 0.04 M TUCS solution, 2 carbonate solvent wash stages and 1 acid rinse stage. This flowsheet has since been tested with simulated SBW in the centrifugal contactor mockup at the ICPP and the results, presented elsewhere [5], support the applicability of the TRUEX process to SBW. The purpose of this work was to verify the behavior of the TRUEX process with samples of actual radioactive SBW. Batch contacts were performed with samples of SBW taken from tank WM-185 and the TRUEX process solvent to verify the extraction, scrub, and stripping behavior with actual waste.

Table 1. Summary of the results obtained for simulated SBW and radioactive tracers $[3,4]$.

\begin{tabular}{|c|c|c|c|c|c|c|c|c|}
\hline \multicolumn{2}{|c|}{$\begin{array}{c}\text { Sample } \\
\text { Description }\end{array}$} & $D_{\text {Am-241 }}$ & $D_{p_{1}-238}$ & $D_{\mathrm{u} \cdot 233}$ & $D_{\mathrm{Np}_{\mathrm{p}-239}}$ & $D_{\text {Tac-95m }}$ & $D_{\mathrm{Zr-95}}$ & $D_{\mathrm{Hg}-203}$ \\
\hline $\begin{array}{l}\text { Forward } \\
\text { Extraction }\end{array}$ & $\begin{array}{l}\text { E1 } \\
\text { E2 } \\
\text { E3 } \\
\end{array}$ & $\begin{array}{l}33 \\
30 \\
27 \\
\end{array}$ & $\begin{array}{l}310 \\
390 \\
420 \\
\end{array}$ & $\begin{array}{l}260 \\
470 \\
600 \\
\end{array}$ & $\begin{array}{l}2.28 \\
1.90 \\
1.40 \\
\end{array}$ & $\begin{array}{l}4.01 \\
4.57 \\
4.10 \\
\end{array}$ & $\begin{array}{l}73 \\
61 \\
52 \\
\end{array}$ & $\begin{array}{l}3.0 \\
3.1 \\
3.1 \\
\end{array}$ \\
\hline $\begin{array}{l}0.2 \underline{\mathrm{M}} \mathrm{HNO}_{3} \\
\text { Scrubs }\end{array}$ & $\begin{array}{l}\mathrm{Sc} 1 \\
\mathrm{Sc} 2 \\
\mathrm{Sc3} \\
\end{array}$ & $\begin{array}{l}19.5 \\
9.3 \\
4.9 \\
\end{array}$ & $\begin{array}{l}94.5 \\
44.5 \\
20.5 \\
\end{array}$ & $\begin{array}{l}470 \\
260 \\
150 \\
\end{array}$ & $\begin{array}{l}3.0 \\
0.4 \\
0.9 \\
\end{array}$ & $\begin{array}{l}10.7 \\
12.6 \\
11.7 \\
\end{array}$ & $\begin{array}{r}25 \\
15 \\
9.4 \\
\end{array}$ & $\begin{array}{l}24 \\
47 \\
56 \\
\end{array}$ \\
\hline $\begin{array}{l}0.01 \mathrm{MNNO}_{3} \\
\text { Strips }\end{array}$ & $\begin{array}{l}\text { St } 1-N \\
\text { St2-N } \\
\text { St3-N } \\
\end{array}$ & $\begin{array}{l}0.69 \\
0.18 \\
0.91 \\
\end{array}$ & $\begin{array}{l}6.0 \\
1.6 \\
22 \\
\end{array}$ & $\begin{array}{l}33 \\
7.6 \\
3.3 \\
\end{array}$ & $\begin{array}{c}2.6 \\
1.8 \\
0.37 \\
\end{array}$ & $\begin{array}{c}7.8 \\
1.5 \\
0.65 \\
\end{array}$ & $\begin{array}{l}\text { No } \\
\text { Data }\end{array}$ & $\begin{array}{l}71 \\
68 \\
67 \\
\end{array}$ \\
\hline $\begin{array}{l}0.1 \\
\text { Strips }\end{array}$ & $\begin{array}{l}\text { St1-O } \\
\text { St2-O } \\
\text { St3-O }\end{array}$ & $\begin{array}{r}0.09 \\
0.02 \\
\text { TBDL } \\
\end{array}$ & $\begin{array}{l}0.24 \\
\text { No } \\
\text { Data }\end{array}$ & $\begin{array}{l}2.38 \\
0.81 \\
0.59 \\
\end{array}$ & $\begin{array}{l}\text { No } \\
\text { Data }\end{array}$ & $\begin{array}{l}1.94 \\
\text { No } \\
\text { Data }\end{array}$ & $\begin{array}{l}\text { No } \\
\text { Data }\end{array}$ & $\begin{array}{c}54 \\
\text { No } \\
\text { Data }\end{array}$ \\
\hline $\begin{array}{l}\text { TUCS } \\
\text { Strips }\end{array}$ & $\begin{array}{l}\text { St1-T } \\
\text { St2-T } \\
\text { St3-T } \\
\end{array}$ & $\begin{array}{r}0.0005 \\
\mathrm{TBDL} \\
\mathrm{tBDL} \\
\end{array}$ & $\begin{array}{c}0.0021 \\
2.8 \\
2.1 \\
\end{array}$ & $\begin{array}{l}0.0003 \\
\text { tBDL } \\
\text { tBDL } \\
\end{array}$ & $\begin{array}{l}2.28 \\
1.90 \\
1.40 \\
\end{array}$ & $\begin{array}{l}6.7 \\
4.2 \\
2.9 \\
\end{array}$ & $\begin{array}{l}0.006 \\
\text { TBDL } \\
\text { tBDL }\end{array}$ & $\begin{array}{l}110 \\
130 \\
130 \\
\end{array}$ \\
\hline $\begin{array}{l}0.25 \underline{\mathrm{M}} \\
\mathrm{Na}_{2} \mathrm{CO}_{3} \\
\text { Solvent Wash }\end{array}$ & $\begin{array}{l}\text { W1-C } \\
\text { W2-C }\end{array}$ & $\begin{array}{l}0.003 \\
\text { tBDL }\end{array}$ & $\begin{array}{c}0.0026 \\
0.8\end{array}$ & $\begin{array}{c}0.0031 \\
\mathrm{TBDL}\end{array}$ & $\begin{array}{l}\text { No } \\
\text { Data }\end{array}$ & $\begin{array}{l}\text { No } \\
\text { Data }\end{array}$ & $\begin{array}{l}\text { tBDL } \\
\text { tBDL }\end{array}$ & $\begin{array}{r}0.08 \\
\text { tBDL }\end{array}$ \\
\hline
\end{tabular}

$\mathrm{BDL}=$ Below Detection Limits: Activity in the organic or aqueous phase was below analytical detection limits. 
The results presented in Table 1 are directly relevant to the results subsequently presented regarding this study. First, the experimental flowsheets used to generate the data in Table 1 incorporated a series of batch contacts performed in a virtually identical manner to the one used in the second experiment (vide infra, refer to Figure 2). However, the organic phase in the tracer tests was pre-equilibrated with unspiked SBW simulant to load the solvent with all extractable matrix components prior to the extractions with radionuclide spiked feed. Thus, the distribution coefficients listed in Table 1 accurately approximate true equilibrium distribution for the given species. Since the TRUEX solvent was pre-equilibrated with nitric acid in the following tests, the resulting distribution coefficients may be slightly different from those listed in Table 1. Secondly, the distributions listed in Table 1 were based on the direct analysis of both the organic and aqueous raffinates from a specified contact, an option that was not available in the tests with samples of WM-185 waste. Thus, a reasonable comparison between the data obtained in this study with that in Table 1 provides some certainty in the experimental and analytical procedures used with the real waste, as well as an indication that the simulated waste is an appropriate surrogate for actual SBW.

The purpose of the stripping contacts with the different reagents was simply to evaluate the efficiency for back-extracting each of the listed species with the various strip solutions. Since actinide fractionation (i.e., partitioning Am from $\mathrm{Pu}$ ) is not planned for ICPP wastes, a gross actinide stripping reagent is beneficial in that the process flowsheet would be greatly simplified. Nitric acid does not strip either Pu or U effectively. With the exception of U, oxalate compounds are typically very effective at stripping the actinides from loaded TRUEX solvent. In numerous tests, including those performed in conjunction with Table 1, the use of dilute oxalate, either $\mathrm{H}_{2} \mathrm{C}_{2} \mathrm{O}_{4}$ or $\left(\mathrm{NH}_{4}\right)_{2} \mathrm{C}_{2} \mathrm{O}_{4}$, have resulted in precipitate formation in the first several strip contacts. Furthermore, material balances in the oxalate strips consistently indicate Am is lost from solution, attributed to the formation of solid americium oxalate, $\operatorname{Am}_{2}\left(\mathrm{C}_{2} \mathrm{O}_{4}\right)_{3}$. Solids formation is an undesirable result from a processing standpoint and studies with oxalate strips have largely been abandoned.

Of the reagents tested, thermally unstable complexants (TUCS) [6] were the only class of compounds which provide gross metal stripping from the organic phase. TUCS compounds are organic derivatives of diphosphonic acid which, as the name implies, can be thermally degraded to $\mathrm{CO}_{2}$ and phosphoric acid. The specific TUCS reagent used in this study was 1-hydroxyethyl1,1-diphosphonic acid (HEDPA). While the TUCS reagent is particularly effective for stripping actinides from the loaded TRUEX solvent, the phosphorus has a deleterious effect on glass waste forms, which typically can withstand phosphorus loading only in the $1-3 \mathrm{wt} \%$ range.

Consequently, phosphorus content resulting in the TUCS strip can have a significant impact on the final volume of HLW glass produced [7]. However, it is known that the concentration of the TUCS solution used in this study, $0.25 \mathrm{M}$, can be substantially reduced, to about $0.04 \underline{\mathrm{M}}$, without measurable impact on the stripping behavior [4]. The phosphate in the HAW stream may still be too high, even with the reduced TUCS concentration; therefore, alternatives to TUCS strip solutions are currently under investigation. 


\section{EXPERIMENTAL}

\section{Reagents}

The active extractant in the TRUEX solvent, CMPO >97\% pure from Elf Atochem, was used as received. Horwitz et. al. report manufacturing impurities in the CMPO have deleterious effects on americium stripping [8]. Studies performed at the ICPP indicate the benefits of purifying the as received CMPO are insufficient to warrant the time consuming purification process [9], particularly for the large quantities required in plant scale implementation. TRUEX solvent was prepared by the Quality Control Laboratory at the ICPP and was 0.2 M CMPO, 1.4 M tributylphosphate 99\% pure from Fluka Ag, in Isopar L (Exxon). The Isopar L diluent is a mixture of synthetic, branched chain, paraffinic hydrocarbons. While previous work at the ICPP used n-dodecane as the diluent, the switch to Isopar L eliminated third phase formation, i.e., a second organic phase, prevalent at the high solvent loadings encountered with solutions of dissolved calcines. The use of Isopar L has no measurable impact on actinide distributions.

\section{Contacting Methodology}

SBW samples taken from tank WM-185 were used as the feed in the extraction experiments. The waste was vacuum filtered through $0.2 \mu \mathrm{m}$ cellulose nitrate filters prior to the TRUEX contacts. Two test scenarios were performed. Test one used three contacts on a single aliquot of WM-185 waste, fresh, pre-equilibrated organic solvent being used in each contact.

The primary purpose of these contacts was to determine distribution coefficients for the forward extraction of the isotopes of interest and to allow elucidation of decontamination factors.

Scrubbing and oxalate strips of the loaded organic from the first extraction contact were also tested. The second test scenario consisted of a single aliquot of TRUEX solvent contacted two successive times with fresh aliquots of SBW from WM-185. The organic phase from the second extraction contact was thereby heavily loaded with the extractable species in the aqueous feed. This loaded organic solvent was then stripped and washed with the appropriate aqueous solutions in a series of batch contacts. This test scenario allowed the determination of extraction, scrubbing, and stripping distribution coefficients under conditions of heavily loaded solvents.

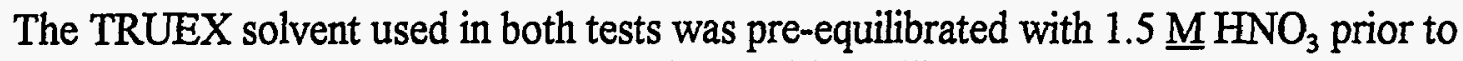
contact with the WM-185 waste to load the solvent with equilibrium concentrations of nitric acid. Pre-equilibration of the solvent was performed by contacting a given volume of the solvent thrice with an equal volume of fresh nitric acid solution (1.5 $\left.\underline{\mathrm{M}} \mathrm{HNO}_{3}\right)$. The pre-equilibrations were performed outside the hot cell in a $500 \mathrm{~mL}$ separatory funnel with mixing accomplished by hand shaking for 3 to 5 minutes. Phase disengagement was performed by allowing the phases to stand and segregate only under the influence of gravity for no less than 30 minutes.

The batch contacts with feed solutions from tank WM-185 were performed in the Remote Analytical Laboratory (RAL). This waste solution is far too radioactive to be handled directly; therefore, the experiments had to be designed to perform many operations remotely in the hot 
cell at the RAL via manipulators. All contacts, with a single exception, were performed at an organic-to-aqueous phase ratio of unity $(\mathrm{O} / \mathrm{A}=1)$. Volumes of WM-185 waste and TRUEX solvent were measured using graduated cylinders. The measured organic and aqueous phases were poured into a polyethylene bottle, which was then capped and shaken with the manipulator for three minutes to provide efficient contacting of the two phases. The contents were then poured into a clean glass separatory funnel. The phases were allowed to gravity separate for five to fifteen minutes to effect phase disengagement. Samples of the aqueous phase were taken for analysis and the appropriate phase was transferred to the next contact. All labware was used only once to prevent cross contamination from occurring during the various contacts. The interface region, consisting of 2 to $5 \mathrm{ml}$, was always discarded to further inhibit crosscontamination between phases. Samples taken for analysis were stored in glass bottles to prevent degradation of the sample container, decreasing the potential for contamination.

\section{Distribution Coefficients}

The primary measure used to evaluate the effectiveness of the solvent to partition various species from the aqueous feed is the distribution coefficient, defined as:

$$
D_{\mathrm{X}}=\frac{[\mathrm{X}]_{\text {organic }}}{[\mathrm{X}]_{\text {aqueous }}}
$$

where $[\mathrm{X}]$ is the concentration of the species of interest in the respective organic or aqueous phase. Note that the larger the $\mathrm{D}$ value, the more material transferred to the organic phase. Conversely, the smaller the distribution coefficient, the greater the amount of the particular species in the aqueous phase. Large distributions are desirable in the extraction and scrub steps for the species of interest, such as the actinides, indicating these species favor the organic phase. Small distribution coefficients $\left(D_{X} \ll 1\right)$ are desirable in the strip contacts, indicating the species is readily removed from the organic phase.

Compositions of the organic phase could not be directly determined with current ICPP analytical methods and were determined indirectly by material balances. Equation (2) can be rewritten using material balances and assuming equal organic and aqueous volumes:

$$
\mathrm{D}_{\mathrm{X}}=\frac{[\mathrm{X}]_{\text {in }}-[\mathrm{X}]_{\text {aqueous }}}{[\mathrm{X}]_{\text {aqueous }}}
$$

where $[X]_{\text {aqueous }}$ is the analytically determined equilibrium concentration of component $X$ in the aqueous raffinate from a given contact. The $[\mathrm{X}]_{\text {in }}$ term is the concentration of species $\mathrm{X}$ in the organic phase calculated from the previous contact. This use of material balances often results in significant errors since even small analytical errors in the aqueous phase analyses are propagated for all subsequently calculated organic phase compositions. Furthermore, experimental errors, associated primarily with volume measurements in graduated cylinders, can be significantly amplified by this methodology. 


\section{Characterization of WM-185 Waste}

Samples of sodium bearing waste from tank WM-185 were submitted for analysis to characterize the "feed" composition and the results are listed in Table 2. These compositions were used in evaluating all distribution data associated with the discussed experiments. It is apparent from Table 2 that major matrix constituents are sodium, nitrate and acid. Rather large quantities of aluminum and potassium are also present. The only inert matrix components anticipated to be extracted by the TRUEX solvent were zirconium, iron, and mercury. Note that all non-radioactive elements are in great excess relative to the radioactive constituents. The individual concentrations of ${ }^{137} \mathrm{Cs},{ }^{90} \mathrm{Sr}$ and combined concentration of ${ }^{238} \mathrm{Pu}$ and ${ }^{239} \mathrm{Pu}$ are only $\sim 10^{-5} \underline{\mathrm{M}}$ and are extremely small on a mass basis. Most of the alpha radioactivity in WM-185 is associated with $\mathrm{Pu}$ and $\mathrm{Am}$. Uranium, although present on a much larger mass basis, contributes less to the $\alpha$ radioactivity than $\mathrm{Pu}$ or $\mathrm{Am}$. A small amount of neptunium is also present.

Table 2. Composition of tank WM-185 waste.

\begin{tabular}{|c|c|c|c|c|c|}
\hline Element & Units & Composition & Element & Units & Composition \\
\hline Acid & $\underline{N}$ & 1.62 & Sulfate & $\underline{\mathrm{M}}$ & 0.017 \\
\hline Aluminum & $\underline{\mathrm{M}}$ & 0.674 & Zirconium & $\underline{\mathrm{M}}$ & 0.0095 \\
\hline Boron & $\underline{\mathrm{M}}$ & 0.019 & Gross $\alpha$ & $\mathrm{dps} / \mathrm{ml}$ & $3.14 \mathrm{E}+04$ \\
\hline Cadmium & $\underline{\mathrm{M}}$ & $<0.0019^{\dagger}$ & Gross $\beta$ & $\mathrm{dps} / \mathrm{ml}$ & $1.61 E+07$ \\
\hline Calcium & $\underline{\mathrm{M}}$ & 0.065 & $\mathrm{Am}-241$ & $\mathrm{dps} / \mathrm{ml}$ & $2.92 \mathrm{E}+03$ \\
\hline Total Carbon & $g / 1$ & 0.716 & $\mathrm{Pu}-238$ & $\mathrm{dps} / \mathrm{ml}$ & $1.99 \mathrm{E}+04$ \\
\hline Chloride & $\underline{\mathrm{M}}$ & 0.032 & Pu-239 & $\mathrm{dps} / \mathrm{ml}$ & $2.41 \mathrm{E}+03$ \\
\hline Chromium & $\underline{\mathrm{M}}$ & 0.005 & Np-237 & $\mathrm{dps} / \mathrm{ml}$ & $1.45 \mathrm{E}+02$ \\
\hline Total Cesium & $\underline{M}$ & 0.000034 & U & $\mathrm{g} / 1$ & 0.107 \\
\hline Fluoride & $\underline{\underline{M}}$ & 0.35 & Cs-134 & $\mathrm{dps} / \mathrm{ml}$ & $1.04 E+04$ \\
\hline Iron & $\underline{\mathrm{M}}$ & 0.021 & Cs-137 & $\mathrm{dps} / \mathrm{ml}$ & $4.23 E+06$ \\
\hline Mercury & $\underline{\mathrm{M}}$ & 0.0039 & $\mathrm{Sr}-90$ & $\mathrm{dps} / \mathrm{ml}$ & $4.44 \mathrm{E}+06$ \\
\hline Nitrate & $\underline{\mathrm{M}}$ & 5.17 & Tc-99 & $\mathrm{dps} / \mathrm{ml}$ & $1.41 E+03$ \\
\hline Potassium & $\underline{\underline{M}}$ & 0.19 & Eu-154 & $\mathrm{dps} / \mathrm{ml}$ & $1.62 E+04$ \\
\hline Sodium & $\underline{\underline{M}}$ & 1.41 & $\mathrm{Co}-60$ & $\mathrm{dps} / \mathrm{ml}$ & $2.47 \mathrm{E}+03$ \\
\hline Total Strontium & $\underline{M}$ & 0.00059 & Sp. Gravity & -- & 1.26 \\
\hline
\end{tabular}

Analyses include contributions from both the stable and radioactive isotopes.

tBelow the analytical detection limit. 


\section{RESULTS AND DISCUSSION}

\section{Waste Decontamination Experiment}

The series of batch contacts used in this experiment are depicted schematically in the experimental flowsheet shown in Figure 1. A single aliquot of SBW from tank WM-185 was contacted three successive times with equal volumes of fresh, pre-equilibrated TRUEX solvent. This contacting methodology provides an estimate of the decontamination factors (DF's) that can be anticipated with the TRUEX/SBW system. The organic raffinate from the first extraction, the most heavily loaded organic phase from the extractions, was scrubbed three consecutive times with $0.2 \mathrm{M} \mathrm{HNO}_{3}$ solution. The purpose of scrubbing was to remove nitric acid and matrix metals, primarily $\mathrm{Zr}$ and $\mathrm{Fe}$, co-extracted with the actinides. The reduction in organic phase acidity during scrubbing facilitates subsequent back-extraction of the actinides and fewer stages are required in the strip section. The scrubbed organic was then contacted with equal volumes of $0.1 \mathrm{M}\left(\mathrm{NH}_{4}\right)_{2} \mathrm{C}_{2} \mathrm{O}_{4}$ in $0.01 \mathrm{M} \mathrm{HNO}_{3}$ to elucidate the stripping ability of this solution. A single solvent wash contact was performed with $0.25 \mathrm{M} \mathrm{Na}_{2} \mathrm{CO}_{3}$, typically incorporated in the TRUEX process to remove degradation products and final traces of actinides from the organic.

Figure 1. Experimental flowsheet used in the first SBW test.

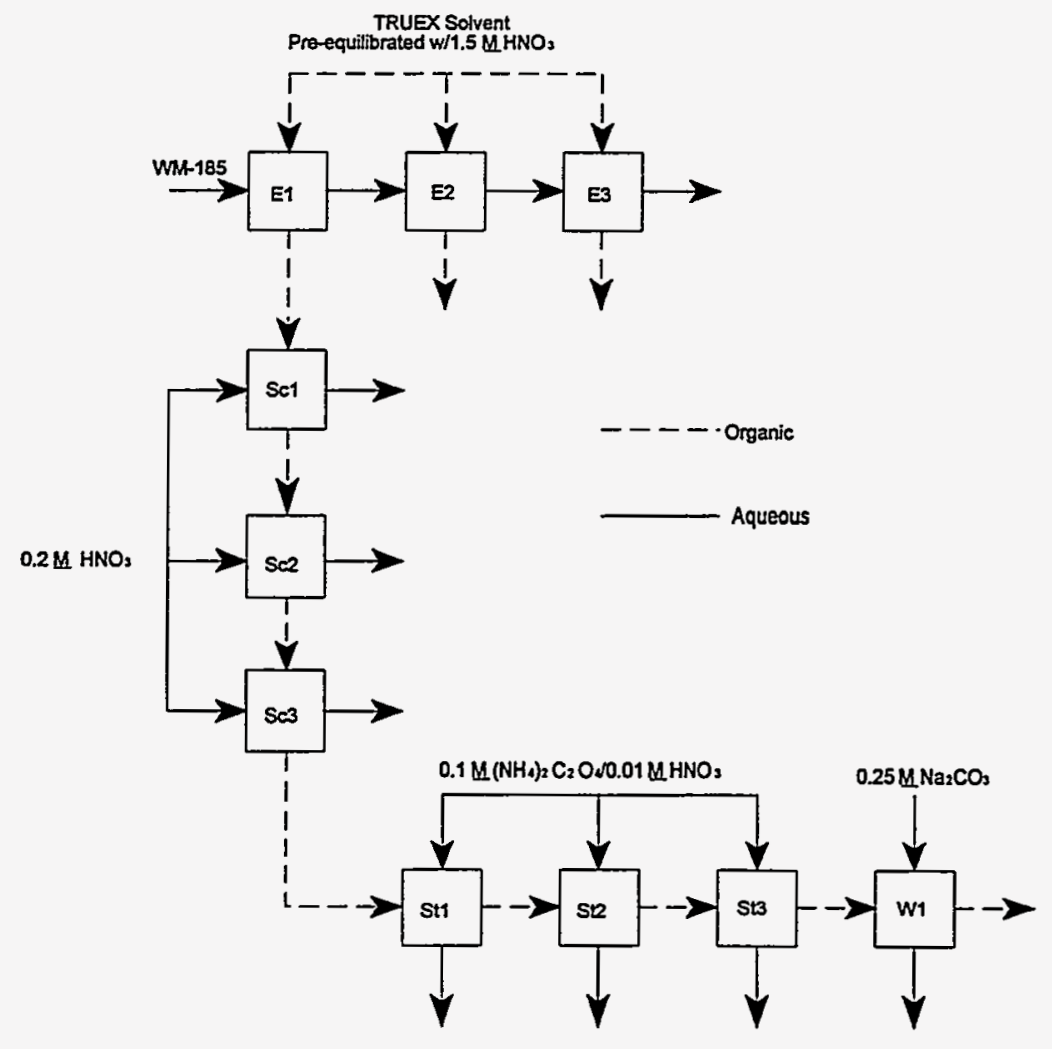


The results from this experimental flowsheet are presented in Table 3 as distribution coefficients for the major components extracted from the feed. Analyses were performed for those elements known to extract significantly into the TRUEX solvent, which include the actinides, zirconium, iron and mercury. Chromium and cadmium extraction was also monitored. The results indicated that detectable amounts of $\mathrm{Cr}$ and $\mathrm{Cd}$ were not extracted from the feed by the TRUEX solvent.

Table 3. Results from the waste decontamination experiment.

\begin{tabular}{|c|c|c|c|c|c|}
\hline \multirow[b]{2}{*}{ Contact } & \multicolumn{5}{|c|}{ Distribution Coefficients } \\
\hline & Gross $\alpha$ & Pu-238 & Pu-239 & Am-241 & Np-237 \\
\hline E1 & 443 & 7,700 & 3,100 & 44 & 65 \\
\hline E2 & 17.5 & ND & ND & 8.0 & 2.4 \\
\hline E3 & 1.46 & $\mathrm{ND}$ & ND & 1.1 & 0.58 \\
\hline Sc1 & 170 & 13,000 & 2,100 & 15 & 24 \\
\hline Sc2 & 80 & 2,300 & 700 & 6.7 & 16 \\
\hline $\mathrm{Sc} 3$ & 49 & 1,250 & 500 & 3.9 & 28 \\
\hline $\mathrm{St}^{\dagger}$ & $<<1^{\dagger}$ & $<<1^{\dagger}$ & $<<1^{\dagger}$ & $48^{\dagger}$ & $0.8^{\dagger}$ \\
\hline$\%$ Recovery & 102 & 105 & 105 & 80.4 & 93.3 \\
\hline Contact & Total U & Zirconium & Iron & \multicolumn{2}{|c|}{ Mercury } \\
\hline E1 & 52 & $>10$ & 1.8 & \multicolumn{2}{|c|}{2.6} \\
\hline E2 & 0.38 & ND & 2.0 & \multicolumn{2}{|c|}{5.6} \\
\hline E3 & $>0.40$ & $\mathrm{ND}$ & 1.6 & \multicolumn{2}{|c|}{5.9} \\
\hline Scl & 104 & $>9.3$ & 0.17 & \multicolumn{2}{|c|}{26} \\
\hline $\mathrm{Sc} 2$ & 103 & 5.0 & 0.88 & \multicolumn{2}{|c|}{45} \\
\hline $\mathrm{Sc} 3$ & 53 & 1.6 & NA & \multicolumn{2}{|c|}{54} \\
\hline $\mathrm{St}^{\dagger}$ & $3.6^{\dagger}$ & $<<1^{\dagger}$ & $\mathrm{NA}$ & \multicolumn{2}{|c|}{$>1^{\dagger}$} \\
\hline$\%$ Recovery & 105 & 104 & 99.1 & \multicolumn{2}{|c|}{104} \\
\hline
\end{tabular}

${ }^{\dagger}$ Distributions for the first strip contact are prone to a great deal of uncertainty due to precipitate formation. 
It is important to note that physical abnormalities such as third phase formation, precipitates, or interfacial crud were not observed in any of the extraction or scrub contacts. Such physical problems typically have deleterious effects on process performance in countercurrent processing equipment and are therefore undesirable. A white precipitate formed in the first strip contact with ammonium oxalate (St1), which settled to the bottom of the aqueous phase. This solid was not isolated for analysis, but was transferred to the sample vial with the aqueous phase. The formation of such precipitates during dilute oxalate strips (with either ammonium oxalate or oxalic acid) have been consistently observed in TRUEX testing of simulated SBW [3]. The exact structure of the precipitate was never identified; however, elemental analysis verified the presence of zirconium and the precipitate is suspected to be a species of zirconium oxalate, perhaps even a polymeric form. The subsequent batch contacts indicated in Figure 1 (St2, St3, W1 and W2) were not performed due to the precipitate formation. Furthermore, the distribution coefficients reported for StI in Table 3 are suspect to a great deal of uncertainty due to material losses associated with entrainment in the solid phase.

This series of batch extraction contacts indicated efficient removal of the actinides and decontamination of the SBW samples from tank WM-185. The waste initially contained a gross $\alpha$ activity of $3.14 \mathrm{E}+04 \mathrm{dps} / \mathrm{mL}$ and the residual gross $\alpha$ activity in the aqueous raffinate from the third extraction contact was only $1.56 \mathrm{dps} / \mathrm{mL}$. The resulting gross $\alpha$ decontamination factor was $\mathrm{DF} \sim 20,000$ after three batch contacts. This corresponds to $99.995 \%$ removal of alpha activity from the feed. Much of the $\alpha$ activity in tank WM-185 waste is attributed to ${ }^{238} \mathrm{Pu}$ and ${ }^{239} \mathrm{Pu}$. The plutonium distribution coefficients are quit high for the first extraction and these isotopes were virtually undetectable in the aqueous raffinate from the first extraction contact. Consequently, the $\mathrm{Pu}$ distributions are meaningless for the E2 and E3. The distribution coefficients for each of the actinides decreased substantially with the successive extraction contacts. This downward trend is attributed to the low activity in the aqueous raffinate from the first extraction, i.e., the actinide concentrations were approaching analytical detection limits. The distributions for the first contact, E1, are the only ones truly representative of equilibrium distributions. The americium distribution in E1, of 44 is in favorable agreement with expected values of $\sim 30$. Neptunium, in the favored +5 oxidation state, is particularly difficult to extract with the TRUEX solvent. Consequently, the neptunium distribution of 65 for the first extraction contact was surprisingly high. This behavior may be attributed to $\mathrm{Np}$ oxidation state partitioning between $\mathrm{Np}(\mathrm{V}), \mathrm{Np}(\mathrm{IV})$, and/or $\mathrm{Np}(\mathrm{VI})$, the later two species being much more extractable in the TRUEX process. The Np oxidation state must be verified in future testing to support this postulate.

The organic raffinate from the first extraction was scrubbed in three successive contacts with fresh aliquots of $0.2 \mathrm{M} \mathrm{HNO}$ to reduce acidity and scrub $\mathrm{Fe}$ and $\mathrm{Zr}$ from the organic prior to stripping the actinides. The distribution coefficients for each of the actinides were much greater than one for each scrub contact, indicating these species indeed remained in the organic phase, which is the desired effect. The distribution coefficient for americium, the easiest of the actinides to remove from the organic, was $\mathrm{D}_{\mathrm{Am}}=3.9$ in the third scrub contact, which is sufficient to insure very little Am would be returned to the extraction section in a countercurrent process. 
Zirconium concentrations were below the analytical detection limits in the aqueous raffinate from the extraction contacts and for the first scrub contact, indicating $\mathrm{Zr}$ was quantitatively extracted from the feed in the first extraction. Unpublished data obtained with simulated SBW and ${ }^{95} \mathrm{Zr}$ tracer (see Table 1) indicate zirconium extraction distributions could be as high as $\mathrm{D}_{\mathrm{zr}}=60$ in the TRUEX solvent. Scrub distributions with $0.2 \mathrm{M} \mathrm{HNO}_{3}$ in the tests with SBW simulant were $\mathrm{D}_{\mathrm{zs}} \sim 10$ (Table 1 ), which agrees very well (considering analytical/ experimental errors) with $\mathrm{D}_{\mathrm{zr}}=1.6$ in the WM-185 experiment. The results obtained in this experiment indicate that $\mathrm{Zr}$ will be significantly extracted from the feed and will not be scrubbed from the organic phase with the $0.2 \mathrm{M} \mathrm{HNO}_{3}$ solution. Consequently, significant quantities of the zirconium, as compared to the actinides, will report to the HAW stream. Promising methods for selectively scrubbing and/or masking $\mathrm{Zr}$ extraction in the processing flowsheet are currently under study at the ICPP and this problem is expected to be alleviated in the future.

The iron distributions obtained in the extraction contacts indicate some iron is extracted from the feed by the TRUEX solvent. However, iron is effectively scrubbed from the organic with $0.2 \mathrm{M} \mathrm{HNO}_{3}$. Indeed, essentially all detectable amounts of iron were removed in the first two scrubs such that iron distribution coefficients are meaningless for the third scrub and each successive contact.

Mercury was also effectively extracted from the feed by the TRUEX process. This behavior was anticipated and parallels results obtained in ${ }^{203} \mathrm{Hg}$ tracer studies with simulated SBW $[10,11]$. It was not anticipated that $\mathrm{Hg}$ would be removed from the organic during the scrubs since previous studies indicate mercury can only be back extracted from the TRUEX solvent with substantially higher nitric acid concentrations $\left(\geq 5 \mathrm{M} \mathrm{HNO}_{3}\right)$ or with sodium carbonate solutions $[10,11]$.

It is important to note that the percent recoveries for most of the species examined were exceptionally close to $100 \%$ despite potential losses to the precipitate formed in the first oxalate strip contact, St1. The primary exception was americium, and the low percent recovery is attributed to the formation of solid $\mathrm{Am}_{2}\left(\mathrm{C}_{2} \mathrm{O}_{4}\right)_{3}$ precipitate [12], as opposed to americium being selectively carried out of solution with the bulk precipitate. The reasonable recoveries for the other species indicate the experimental methods and procedures, including the use of material balances to determine organic phase concentrations, were adequate. This lends a great deal of confidence to the experimental results. 


\section{Solvent Loading \& Stripping Experiment}

Figure 2 indicates the series of batch contacts used in the solvent loading and stripping experiment. The organic solvent was contacted two consecutive times with fresh WM-185 to heavily load the solvent with the extractable species. Note that the organic to aqueous phase ratio in the second extraction contact was $\mathrm{O}: \mathrm{A}=69 \mathrm{~mL} / 55 \mathrm{~mL}=1.255$ since an insufficient amount of the WM-185 feed was readily available at the time the second experiment was performed. The organic raffinate from the second extraction was contacted three successive times with $0.2 \mathrm{M} \mathrm{HNO}_{3}$ to scrub acid and co-extracted matrix materials from the organic phase. The scrubbed organic was split into two separate fractions to test two different strip solutions for back-extraction of the actinides and other metals. One of the fractions was stripped with $0.25 \underline{\mathrm{M}}$ TUCS in three consecutive contacts. The second aliquot of the scrubbed organic was stripped three times with $0.01 \mathrm{M} \mathrm{HNO}_{3}$ solution. Finally, each stripped organic was subjected to $0.25 \mathrm{M}$ $\mathrm{Na}_{2} \mathrm{CO}_{3}$ solvent washes as a cleanup step and to remove final traces of acid and metals that may have remained in the stripped organic phase.

The results of this stripping experiment are presented in Table 4 in terms of the measured distribution coefficients for the pertinent metals extracted by the TRUEX solvent. Aluminum analyses were also performed on the aqueous raffinates from the extraction contacts. As anticipated, Al was not measurably extracted from the WM-185 feed by the TRUEX solvent.

Figure 2. Experimental flowsheet used in the second WM-185 test.
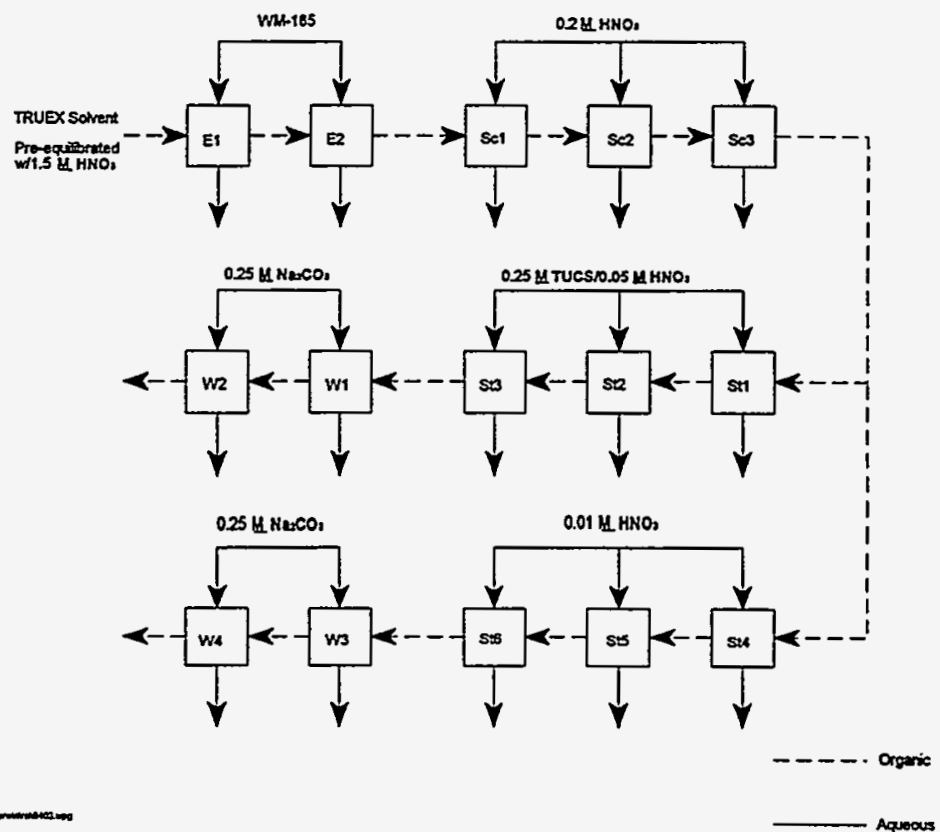
Table 4. Results of the solvent loading and stripping test.

\begin{tabular}{|c|c|c|c|c|}
\hline \multirow[b]{2}{*}{ Contact } & \multicolumn{4}{|c|}{ Distribution Coefficients } \\
\hline & Gross $\alpha$ & $\mathrm{Pu}-238$ & Pu-239 & Am-241 \\
\hline E1 & 430 & 44,000 & 50,000 & 52 \\
\hline E2 & 220 & 26,000 & 18,000 & 29 \\
\hline Scl & 180 & 7,000 & 6,100 & 17 \\
\hline $\mathrm{Sc} 2$ & 99.3 & 4,500 & 4,300 & 8.4 \\
\hline Sc3 & 75.2 & 2,700 & 2,400 & 5.4 \\
\hline StI & 0.036 & $2.8 \mathrm{E}-05$ & $1.4 \mathrm{E}-04$ & $8.0 \mathrm{E}-4$ \\
\hline St2 & 0.33 & 0.21 & 0.39 & 0.19 \\
\hline St4 & 6.1 & 69 & 71 & 0.73 \\
\hline St5 & 1.2 & 3.4 & 3.3 & 0.08 \\
\hline St6 & 4.8 & 9.2 & 9.0 & 0.56 \\
\hline W3 & 0.010 & $2.5 \mathrm{E}-03$ & $2.5 \mathrm{E}-03$ & 0.21 \\
\hline$\%$ Recovery & 92.1 & 115 & 113 & 93.3 \\
\hline Contact & Np-237 & Total U & $\mathrm{Zr}$ & $\mathrm{Fe}$ \\
\hline E1 & 58 & $>110$ & $>10$ & 1.6 \\
\hline E2 & 98 & $>190$ & $>18$ & 1.4 \\
\hline $\mathrm{Sc} 1$ & 25 & $>190$ & 11 & 0.058 \\
\hline $\mathrm{Sc} 2$ & 15 & $>190$ & 4.7 & 0.072 \\
\hline Sc3 & 18 & $>190$ & 1.6 & NA \\
\hline Stl & $1.4 \mathrm{E}-03$ & $\ll<1$ & $<<1$ & NA \\
\hline St2 & NA & NA & NA & NA \\
\hline St4 & 1.5 & 46 & 0.14 & NA \\
\hline St5 & 0.19 & 4.8 & NA & NA \\
\hline St6 & $\ll 1$ & 3.4 & NA & NA \\
\hline W3 & NA & $\ll 1$ & NA & NA \\
\hline \% Recovery & 100 & 75.1 & 102 & 100 \\
\hline
\end{tabular}

NA $=$ Not Applicable 
Parallel to the results from the first test, the extraction contacts indicate reasonably large distribution coefficients for the gross $\alpha$ activity. The gross $\alpha$ distributions for the extractions compare remarkably well with that for E1 in the first experiment. Plutonium, the largest contributor to the $\alpha$ activity in the WM-185 waste, was quantitatively removed in both extraction contacts as indicated by the extremely large distribution coefficients. Residual Pu-238 and Pu239 in the aqueous raffinates were very near the analytical detection limits. Americium, one of the more difficult actinides to exact, also exhibited a substantial distribution coefficient in both extraction contacts. The extraction distribution coefficients for total uranium are listed as greater than numbers since the $U$ concentrations in the aqueous raffinates were below analytical detection limits, indicating significant extraction of uranium from the feed. The Np-237 distributions were quite large, and in accord with the first experiment, this is possibly due to partitioning of $\mathrm{Np}$ between the (V), (IV), and (VI) oxidation states. It is important to realize the differences in the experimental flowsheets when comparing the results from the first experiment (Table 3) to those of the second test. Only the first extraction in Table 3 is directly comparable to the extractions in the solvent loading experiment. The extraction results between the two experiments are generally consist with one another and are largely as expected based on prior tests with SBW simulant as discussed in conjunction with Table 1.

The actinide distribution coefficients for the various scrub contacts with $0.2 \mathrm{M} \mathrm{HNO}_{3}$ are sufficiently high to indicate losses and subsequent return to the extraction section will be minimal. The scrub distributions for each of the actinides compare remarkably well with their respective values determined in the first experiment. The scrub methodology was precisely the same in the two tests; therefore, the excellent agreement of this data provides confidence in the experimental and analytical techniques used in this study.

The zirconium data in Table 4 are consistent with the results of the first experiment and indicate $\mathrm{Zr}$ was effectively extracted from the feed by the TRUEX process solvent. Zirconium in the aqueous extraction raffinates was consistently below analytical detection limits, resulting in indeterminate (greater than) distribution coefficients. Zirconium was not effectively scrubbed with $0.2 \underline{\mathrm{M}} \mathrm{HNO}_{3}$.

Iron was somewhat extracted by the solvent in the first two contacts. The distributions were consistent with those determined in the first experiment and with results obtained with SBW simulant traced with radioactive iron. The $0.2 \mathrm{M} \mathrm{HNO}_{3}$ solution effectively scrubbed iron - from the organic, and the iron was completely back extracted (to within analytical detection limits) after the second scrub contact.

Distribution coefficients for mercury, known to extract from SBW with the TRUEX solvent, were determined only for the extraction contacts in the second experiment. These distributions, although not listed in Table 4 , were $\mathrm{D}_{\mathrm{Hg}}=1.8$ and $\mathrm{D}_{\mathrm{Hg}}=1.2$ in the first and second extractions, respectively. The distributions from the first extraction contacts (E1) in the two experiments are in excellent agreement. 
The strip contacts with $0.25 \underline{\mathrm{M}}$ TUCS indicate this solution was extremely effective at back extracting the actinides and zirconium from the TRUEX solvent. In fact, virtually all detectable traces of the actinides and $\mathrm{Zr}$ were removed in the first strip contact with TUCS, and were certainly gone after the second contact. Distributions in the third strip (St3) and the two carbonate washes (W1, W2) could not be determined due to the excellent efficiency of the TUCS solution to back extract the actinides, or were meaningless due to the lack of activity in the aqueous phase. Consequently, data for these contacts are not included in Table 3 . The data supports the use of HEDPA (the TUCS compound used in this study) as a gross actinide stripping reagent, one of the few known, which will simultaneously back extract all of the actinides from the loaded TRUEX solvent. The distribution coefficients determined in the TUCS contacts suggest an indirect analytical method of determining actinide and metal concentrations in the organic phase for use in future experiments where organic phase concentrations cannot be directly measured. The organic samples (from any of the contacts) would be contacted with $0.25 \underline{\mathrm{M}}$ TUCS solution at high aqueous to organic phase ratios (A:O $\geq$ 5), the TUCS reagent decomposed to phosphoric acid, and the resulting aqueous analysis performed by standard analytical methods. The applicability of such a method is currently being investigated at the ICPP.

The strip contacts with $0.01 \underline{\mathrm{M}} \mathrm{HNO}_{3}$ indicate this solution will strip $\mathrm{Am}, \mathrm{Np}$, and $\mathrm{Zr}$ from the loaded organic. The $\mathrm{Pu}$ and $\mathrm{U}$, as anticipated, are not effectively stripped from the organic with dilute nitric acid. The distribution coefficients for gross $\alpha$ in the dilute acid strips compare reasonably well with the corresponding Pu distributions. This is not surprising since much of the $\alpha$ activity in the feed is associated with $\mathrm{Pu}$.

The organic from the dilute nitric acid strips was contacted twice with $0.25 \mathrm{M} \mathrm{Na}_{2} \mathrm{CO}_{3}$ to test solvent washing. Sodium carbonate is effective at removing the acidic impurities or degradation products and final traces of $U$ from the solvent. The distribution coefficients for $U$ and $\mathrm{Pu}$ support this conclusion. The final detectable traces of $\mathrm{U}, \mathrm{Pu}$, and gross $\alpha$ activity where back extracted from the organic in the first carbonate contact (W3); consequently, data for the final wash contact (W4) is not listed in Table 4.

With the exception of $U$, the percent recovery for each of the species listed in Table 4 is quit reasonable considering the organic phase concentrations were determined by material balance and not directly measured. The low recovery of uranium is attributed to the uncertainty of the aqueous raffinate analyses in the first five contacts, all of which were below the analytical detection limits. The excellent percent recoveries lend confidence to the measured distribution coefficients and experimental methodology which produced them. 


\section{CONCLUSIONS}

The primary purpose of this test was to verify the applicability of the TRUEX process, as developed with simulants and radioactive tracers, to actual radioactive waste samples. The results obtained in this test closely parallel those obtained with simulated SBW and radioactive tracers. The measured distribution coefficients for the actinides and co-extracted matrix metals $\mathrm{Zr}, \mathrm{Fe}$, and $\mathrm{Hg}$, were consistent with these previous studies, with the exception of $\mathrm{Np}$. The rather large neptunium distribution in the extraction contacts is currently attributed to Np oxidation state partitioning. The agreement between the real and simulated wastes lend a great deal of confidence to the use of simulated SBW in future process flowsheet development work.

The results of this test indicate the TRUEX process is certainly amenable to ICPP SBW and will easily reduce the actinide activity to well below the $10 \mathrm{nCi} / \mathrm{g}$ Class A TRU limit. Iron can be readily scrubbed from the organic with a $0.2 \mathrm{M} \mathrm{HNO}_{3}$ solution; however, $\mathrm{Zr}$ is not readily scrubbed from the organic with this nitric acid solution. Alternative methods for selectively scrubbing $\mathrm{Zr}$ from the organic, or masking its extraction, will be required if the $\mathrm{Zr}$ concentrations in the high level waste form (glass or glass ceramic) present a problem.

The TUCS reagent was the most effective of the stripping solutions tested for backextraction of actinides and matrix metals, except $\mathrm{Hg}$, remaining in the scrubbed TRUEX solvent. However, there are some concerns that glass waste forms have a limited capacity for phosphorus loading. Such concern could mitigate the advantages of the TUCS stripping reagent. Oxalate solutions, when used as stripping reagents, result in the formation of precipitates which are undesirable in solvent extraction equipment. Dilute nitric acid is ineffective at stripping $\mathrm{Pu}$ and U from the TRUEX solvent.

These results support the applicability of the suggested baseline TRUEX flowsheet for the treatment of ICPP SBW. This flowsheet has already been tested on a continuous, countercurrent basis with simulated SBW in the centrifugal contactor mockup at the ICPP. Results are presented elsewhere [5], and were in excellent agreement with data from these, and other, batch contact experiments. 
.. - + - 


\section{REFERENCES}

[1] ICPP Radioactive Liquid and Calcine Waste Technologies Evaluation Draft Technical Report, Report INEL-94/0119, Lockheed Idaho Technologies Company, October 1994.

[2] Horwitz, E. P., Kalina, D. G., Diamond, H., Vandegrift, G. F., Solvent Extraction \& Ion Exchange, $\mathbf{3}(1 \& 2), 75(1985)$.

[3] TRUEX Partitioning Studies Applied to ICPP Sodium Bearing Waste, Report WINCO-1206, Westinghouse Idaho Nuclear Co., Inc., May 1994.

[4] Herbst, R. S., Brewer, K. N., Unpublished Data.

[5] TRUEX Flowsheet Development As Applied To ICPP Sodium-Bearing Waste Using Centrifugal Contactors, LITCO Report, In Press, Lockheed Idaho Technologies Co., 1995.

[6] Horwitz, E. P., Diamond, H., Gatrone, R. C., Nash, K. L., Rickert, P. G., "TUCS: A New Class of Aqueous Complexing Agents For Use In Solvent Extraction Processes", Presented at ISEC-90, Kyoto, Japan, July 20, 1990.

[7] Brewer, K. N., Unpublished Data.

[8] Chiarzia, R., Horwitz, E. P., Solvent Extraction \& Ion Exchange, $\underline{\mathbf{8}(6), 907(1990) .}$

[9] CMPO Purity Tests in the TRUEX Solvent Using Americium-241, Report WINCO-1177, Westinghouse Idaho Nuclear Co., Inc., December 1993.

[10] Herbst, R. S., Brewer, K. N., Tranter, T. J., Todd, T. A., Solvent Extraction \& Ion Exchange, 13(3), (1995), In Press.

[11] Brewer, K. N., Herbst, R. S., Tranter, T. J., Todd, T. A., Solvent Extraction \& Ion Exchange, 13(3), 907(1995), In Press.

[12] Leonard, R. A., et. al., Basic TRUEX Process for Rocky Flats Plant, Report ANL-94/33, Argonne National Laboratory, August 1994. 
- _- 
APPENDIX:

EXPERIMENTAL DATA 


\begin{tabular}{|c|c|c|c|c|c|c|c|c|c|}
\hline \multicolumn{10}{|c|}{ TRUEX/MM-185 Test \#1 } \\
\hline & \multirow{2}{*}{\multicolumn{3}{|c|}{\begin{tabular}{|l|} 
Gross Alpha \\
Concentrations (dps/ml)
\end{tabular}}} & Pu-238 & & & Pu-239 & & \\
\hline & & & & \multicolumn{3}{|c|}{ Concentrations (dps/ml) } & \multicolumn{3}{|c|}{ Concentrations (dps/ml) } \\
\hline & Aqueous & Organic & $\bar{D}$ & Aqueous & Organic & $\bar{D}$ & Aqueous & Organic & $\mathrm{D}$ \\
\hline Feed: & $3.14 \mathrm{E}+04$ & & & $1.99 E+04$ & & & $2.41 E+03$ & & \\
\hline \multicolumn{10}{|l|}{ Contact } \\
\hline E1 & 70.7 & $3.13 E+04$ & 443.1301 & 2.6 & $1.99 E+04$ & 7652.846 & 0.784 & $2.41 \mathrm{E}+03$ & 3072.98 \\
\hline E2 & 3.83 & $6.69 \mathrm{E}+01$ & 17.45953 & 7.2 & $0.00 \mathrm{E}+00$ & 0 & 0.825 & $0.00 E+00$ & 0 \\
\hline E3 & 1.56 & $2.27 E+00$ & 1.455128 & 4.8 & $0.00 \mathrm{E}+00$ & 0 & 0.832 & $0.00 E+00$ & $\overline{0}$ \\
\hline Sc1 & 180 & $3.11 E+04$ & 173.0517 & 1.54 & $1.99 E+04$ & 12919.39 & 1.17 & $2.41 E+03$ & 2058.159 \\
\hline Sc2 & 385 & $3.08 E+04$ & 79.90727 & 8.57 & $1.99 \mathrm{E}+04$ & 2320.571 & 3.43 & $2.40 E+03$ & 701.0542 \\
\hline Sc3 & 615 & $3.01 E+04$ & 49.02325 & 16 & $1.99 E+04$ & 1241.956 & 4.84 & $2.40 E+03$ & 495.8215 \\
\hline St1 & $3.17 E+04$ & $0.00 E+00$ & 0 & 22796 & $0.00 E+00$ & 0 & 2760 & $0.00 E+00$ & 0 \\
\hline st2 & 0 & $0.00 \mathrm{E}+00$ & NA & 0 & $0.00 \mathrm{E}+00$ & NA & 0 & $0.00 E+00$ & NA \\
\hline St3 & 0 & $0.00 \mathrm{E}+00$ & $\overline{N A}$ & 0 & $0.00 E+00$ & $\mathrm{NA}$ & 0 & $0.00 E+00$ & NA \\
\hline \multirow{5}{*}{ W1 } & 0 & $0.00 E+00$ & NA & $\overline{0}$ & $0.00 E+00$ & NA & 0 & $0.00 E+00$ & NA \\
\hline & \multicolumn{2}{|c|}{ \% Recovery } & 100.5433 & \multicolumn{2}{|c|}{ \% Recovery } & 104.6031 & \multicolumn{2}{|c|}{$\%$ Recovery } & 104.6722 \\
\hline & $\overline{A m-241}$ & & & Np-237 & & & Uranium & & \\
\hline & \multicolumn{3}{|c|}{ Concentrations (dps/ml) } & \multicolumn{3}{|c|}{ Concentrations (dps/ml) } & \multicolumn{2}{|c|}{ Concentrations ( $\mathrm{g} / \mathrm{l}$ ) } & \\
\hline & Aqueous & Organic & $D$ & Aqueous & Organic & $D$ & Aqueous & Organic & $D$ \\
\hline Feed: & $2.92 \mathrm{E}+03$ & & & $1.45 E+02$ & & & $1.07 \mathrm{E}-01$ & & \\
\hline \multicolumn{10}{|l|}{ Contact } \\
\hline$E 1$ & 65.1 & $2.85 E+03$ & 43.85407 & 2.2 & $1.43 \mathrm{E}+02$ & 64.90909 & $2.02 \mathrm{E}-03$ & $1.05 \mathrm{E}-01$ & 51.9703 \\
\hline E2 & 7.2 & $5.79 E+01$ & 8.041667 & 0.646 & $1.55 \mathrm{E}+00$ & 2.405573 & $1.46 \mathrm{E}-03$ & $5.60 \mathrm{E}-04$ & 0.383562 \\
\hline E3 & 3.5 & $3.70 E+00$ & 1.057143 & 0.41 & 2.36E-01 & 0.57561 & $<0.00104$ & 00042 & $>0.40$ \\
\hline Sc1 & 181 & $2.67 E+03$ & 14.77293 & 5.68 & $1.37 E+02$ & 24.14085 & $<0.001$ & 10398 & $>104$ \\
\hline Sc2 & 347 & $2.33 E+03$ & 6.705764 & 8.33 & $1.29 E+02$ & 15.46098 & $<0.001$ & $>0.10298$ & $>103$ \\
\hline $\mathrm{Sc3}$ & 475 & $1.85 E+03$ & 3.898737 & 4.41 & $1.24 \mathrm{E}+02$ & 28.20408 & $1.89 \mathrm{E}-03$ & $1.01 \mathrm{E}-01$ & 53.48677 \\
\hline St1 & 38 & $1.81 E+03$ & 47.73421 & 68 & $5.64 \mathrm{E}+01$ & 0.829118 & $2.18 \mathrm{E}-02$ & $7.93 \mathrm{E}-02$ & 3.637156 \\
\hline St2 & 0 & $0.00 E+00$ & $\mathrm{NA}$ & 0 & $0.00 E+00$ & NA & $7.70 E-04$ & $7.85 E-02$ & 101.974 \\
\hline St3 & 0 & $0.00 E+00$ & NA & 0 & $0.00 \mathrm{E}+00$ & $\overline{\mathrm{NA}}$ & $<0.0006$ & 07792 & $>130$ \\
\hline \multirow[t]{5}{*}{ W1 } & 0 & $0.00 E+00$ & $\mathrm{NA}$ & 0 & $0.00 \mathrm{E}+00$ & NA & $7.79 E-02$ & $0.00 E+00$ & $\ll 1$ \\
\hline & \multicolumn{2}{|c|}{$\%$ Recovery } & 79.40454 & \multicolumn{2}{|c|}{$\%$ Recovery } & 92.31703 & \multicolumn{2}{|c|}{$\%$ Recovery } & 104.63 \\
\hline & \multicolumn{2}{|l|}{ Zirconium } & & \multicolumn{2}{|l|}{\begin{tabular}{|l|l|} 
Iron & \\
\end{tabular}} & & \multicolumn{2}{|l|}{ Mercury } & \\
\hline & Concentrat & ions (mol/l) & & Concentrat & ions $(\mathrm{mol} / \mathrm{l})$ & & Concentrati & $\mathrm{mol} / \mathrm{l})$ & \\
\hline & Aqueous & Organic & $\bar{D}$ & Aqueous & Organic & $\bar{D}$ & Aqueous & Organic & $\bar{D}$ \\
\hline Feed: & $9.50 \mathrm{E}-03$ & & & \begin{tabular}{|c|}
$2.10 \mathrm{E}-02$ \\
\end{tabular} & & & \begin{tabular}{|c|}
$3.90 \mathrm{E}-03$ \\
\end{tabular} & & \\
\hline Contact & & & & & & & & & \\
\hline$E 1$ & $<0.000837$ & $8.66 \mathrm{E}-03$ & $>10$ & $7.45 \mathrm{E}-03$ & $1.36 \mathrm{E}-02$ & 1.818792 & $1.07 E-03$ & $2.83 \mathrm{E}-03$ & 2.64486 \\
\hline E2 & $<0.000837$ & $0.00 E+00$ & NA & $2.47 E-03$ & $4.98 \mathrm{E}-03$ & 2.016194 & $1.62 E-04$ & BE-04 & 5.604938 \\
\hline E3 & $<0.000837$ & $0.00 E+00$ & $\mathrm{NA}$ & $9.50 \mathrm{E}-04$ & $1.52 \mathrm{E}-03$ & 1.6 & $2.35 \mathrm{E}-05$ & $1.39 \mathrm{E}-04$ & 5.893617 \\
\hline Sc1 & $<0.00084$ & $7.82 \mathrm{E}-03$ & $>9.3$ & $1.16 E-02$ & $1.95 E-03$ & 0.168103 & $1.03 E-04$ & $2.73 E-03$ & 26.47573 \\
\hline Sc2 & 0.0013 & $6.52 \mathrm{E}-03$ & 5.017692 & $1.04 E-03$ & $9.10 \mathrm{E}-04$ & 0.875 & $5.93 E-05$ & $2.67 \mathrm{E}-03$ & 44.98651 \\
\hline Sc3 & 0.0025 & $4.02 \mathrm{E}-03$ & 1.6092 & $<0.000092$ & $>0.00082$ & NA & $4.89 E-05$ & $2.62 \mathrm{E}-03$ & 53.55419 \\
\hline St1 & 0.00434 & $0.00 \mathrm{E}+00$ & $<1$ & $<0.00009$ & $>0.00073$ & NA & $0.00 E+00$ & $2 E-03$ & NA \\
\hline St2 & $<0.0008$ & $0.00 E+00$ & NA & $<0.00009$ & $>0.00064$ & NA & $0.00 \mathrm{E}+00$ & $2.62 E-03$ & NA \\
\hline St3 & $<0.0008$ & $0.00 \mathrm{E}+00$ & NA & $<0.00009$ & $>0.00055$ & NA & $0.00 E+00$ & $2.62 E-03$ & NA \\
\hline W1 & 0 & $0.00 E+00$ & NA & $0.00 \mathrm{E}+00$ & $5.49 \mathrm{E}-04$ & NA & $2.62 \mathrm{E}-03$ & 0 & $<1$ \\
\hline & $\%$ Recover & & 103.3898 & $\%$ Recover & & 100.2168 & $\%$ Recoven & & 104.2083 \\
\hline
\end{tabular}




\begin{tabular}{|c|c|c|c|c|c|c|c|c|c|}
\hline \multicolumn{10}{|c|}{ TRUEXMM-185 Test \#2 } \\
\hline & \multirow{2}{*}{\multicolumn{3}{|c|}{\begin{tabular}{|l|} 
Gross Alpha \\
Concentrations (dps/ml)
\end{tabular}}} & $P u-238$ & & & Pu-239 & & \\
\hline & & & & \multicolumn{3}{|c|}{ Concentrations (dps/ml) } & \multicolumn{3}{|c|}{ Concentrations (dps/ml) } \\
\hline & Aqueous & Organic & D & Aqueous & Trganic & D & Aqueous & Organic & D \\
\hline Feed: & $3.14 \mathrm{E}+04$ & & & $1.99 E+04$ & & & $2.41 E+03$ & & \\
\hline \multicolumn{10}{|l|}{ Contact } \\
\hline$E 1$ & 72.15 & $3.13 E+04$ & 434.2342 & 0.45 & $1.99 E+04$ & 44222.22 & 0.048 & $2.41 E+03$ & 50208.33 \\
\hline$E 2$ & 235.3 & $5.17 E+04$ & 219.592 & 1.39 & $3.57 E+04$ & 25683.45 & 0.24 & $4.33 E+03$ & 18045.83 \\
\hline Se1 & 308 & $5.59 E+04$ & 181.3636 & 5.1 & $3.57 E+04$ & 7000 & 0.71 & $4.33 E+03$ & 6098.592 \\
\hline Sc2 & 557 & $5.53 E+04$ & 99.28187 & 8 & $3.57 E+04$ & 4462.5 & 1 & $4.33 E+03$ & 4329 \\
\hline$\overline{S c 3}$ & 745 & $5.61 E+04$ & 75.2349 & 13.1 & $3.57 E+04$ & 2725.191 & 1.8 & $4.33 E+03$ & 2403,889 \\
\hline St1 & 59800 & 2140 & 0.035786 & 48400 & 1.37 & 2.83E-05 & 5810 & 0.823 & 0.000142 \\
\hline St2 & 1610 & 529 & 0.328571 & 1.127 & 0.243 & 0.215617 & 0.591 & 0.232 & 0.392555 \\
\hline $\mathbf{S t 3}$ & 529.5 & 0 & 0 & 0.243 & 0 & 0 & 0.232 & 0 & 0 \\
\hline$S+4$ & 6170 & 37363.5 & 6.055673 & 581 & 39847.1 & 68.58365 & 66 & 4656 & 70.54545 \\
\hline $5+5$ & 16850 & 20512.5 & 1.217359 & 9100 & 30747.1 & 3.378802 & 1080 & 3576 & 3.311111 \\
\hline St6 & 3545 & 16967.5 & 4.786319 & 3009 & 27738.1 & 9.218378 & 358 & 3218 & 8.988827 \\
\hline W3 & 16800 & 167.5 & 0.00997 & 27670 & 68.1 & 0.002461 & 3210 & 8 & 0.002492 \\
\hline \multirow[t]{5}{*}{ W4 } & 167.5 & 0 & 0 & 68.1 & $\overline{0}$ & 0 & 8 & 0 & 0 \\
\hline & \multicolumn{2}{|l|}{$\%$ Recovery } & 92.09969 & \multicolumn{2}{|c|}{$\%$ Recovery } & 114.7983 & \multicolumn{2}{|l|}{$\%$ Recovery } & 112.6971 \\
\hline & $A m-241$ & & & $N p-237$ & & & Uranium & & \\
\hline & \multicolumn{3}{|c|}{ Concentrations (dps/ml) } & \multicolumn{3}{|c|}{ Concentrations (dps/ml) } & \multicolumn{2}{|c|}{ Concentrations $(\mathrm{g} / \mathrm{l})$} & \\
\hline & Aqueous & Organic & D & Aqueous & Organic & D & Aqueous & Organic & D \\
\hline Feed: & $2.92 E+03$ & & & $1.45 \mathrm{E}+02$ & & & $1.07 E-01$ & & \\
\hline \multicolumn{10}{|l|}{ Contact } \\
\hline E1 & 55 & $2.87 E+03$ & 52.09091 & 2.45 & $1,43 E+02$ & 58.36735 & $<0.001$ & $>0.106$ & $>106$ \\
\hline E2 & 175 & $5.05 E+03$ & 28.87429 & 2.6 & $2.56 \mathrm{E}+02$ & 98.46154 & $<0.001$ & $>0.19$ & $>190$ \\
\hline Sel & 281 & 4.77E+03 & 16.98221 & 9.9 & $2.46 E+02$ & 24.84848 & $<0.001$ & $>0.189$ & $>189$ \\
\hline $\mathrm{Sc2}$ & 509 & $4.26 E+03$ & 8.375246 & 15.1 & $2.31 E+02$ & 15.29801 & $<0.001$ & $>0.188$ & $>188$ \\
\hline Sc3 & 662 & $3.60 E+03$ & 5.439577 & 12 & $2.19 E+02$ & 18.25 & $<0.001$ & $>0.187$ & $>187$ \\
\hline St1 & 3370 & 2.7 & 0.000801 & 350 & 0.485 & 0.001386 & $>0.184$ & 0 & $\ll 1$ \\
\hline St2 & 2.3 & 0.428 & 0.186087 & 0.485 & 0 & 0 & $<0.0006$ & 0 & 0 \\
\hline St3 & 0.428 & $\cdot \mathbf{0}$ & 0 & 0 & 0 & & $<0.0006$ & 0 & 0 \\
\hline St4 & 2017 & 1472 & 0.729797 & 44 & 67.06 & 1.524091 & 0.0021 & 0.0957 & 45.57143 \\
\hline St5 & 1360 & 112 & 0.082353 & 56.06 & 11 & 0.196218 & 0.0165 & 0.0792 & 4.8 \\
\hline St6 & 72 & 40 & 0.555556 & 11 & 0 & 0 & 0.0182 & 0.061 & 3.351648 \\
\hline W3 & 33 & 7 & 0.212121 & 0 & 0 & & 0.061 & $<0.0006$ & $<0.10$ \\
\hline \multirow[t]{5}{*}{ W4 } & 7 & 0 & 0 & 0 & 0 & & $<0.0006$ & 0 & 0 \\
\hline & \multicolumn{2}{|l|}{$\%$ Recovery } & 80.40454 & \% Recover & & 100.2335 & \% Recoven & & 75.08935 \\
\hline & Zirconium & & & Iron & & & Mercury & & \\
\hline & Concentrat & jons (molli) & & Concentrat & tions (moll) & & Concentrati & tions $(\mathrm{mol} / \mathrm{l})$ & \\
\hline & Aqueous & Organic & D & Aqueous & Organic & D & Aqueous & Organic & D \\
\hline Feed: & \begin{tabular}{|c|}
$9.50 \mathrm{E}-03$ \\
\end{tabular} & & & \begin{tabular}{|c|}
$2.10 \mathrm{E}-02$ \\
\end{tabular} & & & \begin{tabular}{|l|}
$3.90 \mathrm{E}-03$ \\
\end{tabular} & & \\
\hline Contact & & & & & & & & & \\
\hline E1 & $8.40 \mathrm{E}-04$ & $8.66 E-03$ & 10.30952 & 0.0082 & $1.28 \mathrm{E}-02$ & 1.560976 & \begin{tabular}{|l|}
$1.40 \mathrm{E}-03$ \\
\end{tabular} & $2.50 \mathrm{E}-03$ & 1.78 \\
\hline E2 & $8.40 \mathrm{E}-04$ & $1.52 \mathrm{E}-02$ & 18.09524 & 0.0137 & $1.86 E-02$ & 1.357664 & $2.90 \mathrm{E}-03$ & $3.60 \mathrm{E}-03$ & 1.24 \\
\hline Set & 0.00135 & 1.43E-02 & 10.59259 & 0.0176 & $1.00 E-03$ & 0.056818 & & & \\
\hline Sc2 & 0.00249 & $1.18 E-02$ & 4.742972 & 0.00095 & $6.88 \mathrm{E}-05$ & 0.072421 & & & \\
\hline Sc3 & 0.00457 & $7.24 E-03$ & 1.584245 & $9.00 \mathrm{E}-05$ & $0.00 E+00$ & 0 & & & \\
\hline St1 & 0.00724 & 0 & 0 & 0 & 0 & & & & \\
\hline St2 & $8.10 \mathrm{E}-04$ & 0 & 0 & 0 & 0 & & & & \\
\hline St3 & $8.10 E-04$ & 0 & 0 & 0 & 0 & & & & \\
\hline St4 & 0.00609 & 0 & 0 & 0 & 0 & & & & \\
\hline St5 & $8.14 \mathrm{E}-04$ & 0 & 0 & 0 & 0 & & & & \\
\hline St6 & $8.14 E-04$ & 0 & 0 & 0 & 0 & & & & \\
\hline W3 & NA & 0 & 0 & 0 & 0 & & & & \\
\hline W4 & NA & 0 & 0 & 0 & 0 & & & & \\
\hline & $\%$ Recovery & & 101.8127 & \% Recover & & 100.0464 & & & \\
\hline
\end{tabular}

